\title{
Hyperconnectivity Between The Posterior Cingulate and Middle Frontal and Temporal Gyrus in Depression: Based On Functional Connectivity Meta-Analyses.
}

\author{
Ziqing Zhu \\ Southern Medical University \\ You Wang \\ Southern Medical University \\ Way Lau \\ The Education University of Hong Kong \\ Xinhua Wei \\ Guangzhou Medical College First Affiliated Hospital \\ Yingjun Liu \\ Southern Medical University \\ Ruiwang Huang \\ South China Normal University \\ Ruibin Zhang ( $\square$ ruibinzhang@foxmail.com ) \\ Southern Medical University https://orcid.org/0000-0003-1766-8237
}

\section{Research Article}

Keywords: posterior cingulate, resting-state functional connectivity, meta-analysis

Posted Date: July 7th, 2021

DOI: https://doi.org/10.21203/rs.3.rs-633328/v1

License: @) (i) This work is licensed under a Creative Commons Attribution 4.0 International License. Read Full License

Version of Record: A version of this preprint was published at Brain Imaging and Behavior on January 28th, 2022. See the published version at https://doi.org/10.1007/s11682-022-00628-7. 


\section{Abstract}

\section{Background}

Disrupted whole-brain resting-state functional connectivity (RSFC) of the posterior cingulate (PCC) has been highlighted to associate with cognitive and affective dysfunction in major depressive disorder (MDD). However, prior findings showed certain inconsistency about the RSFC of the PCC in MDD. This study aims to investigate the aberrant RSFC of the PCC in MDD using anisotropic effect-size version of seed-based d mapping (AES-SDM).

\section{Methods}

Web of Science and PubMed were searched for studies investigating PCC-based RSFC in MDD. A total of 17 studies, involving 804 patients and 724 healthy controls (HCs), fit our selection criteria. Additionally, to seek for the link between functional and structural differences, we did a metaanalysis on the studies in conjunction with Voxel-based morphology (VBM) analysis.

\section{Results}

The PCC showed higher RSFC with the left middle temporal gyrus (MTG) and the right middle frontal gyrus (MFG), and lower RSFC with the left superior frontal gyrus (SFG) and the left precuneus in patients with MDD than HCs. Notably, the left MTG and the left MFG were the overlapped regions of aberrant VBM and RSFC results.

\section{Conclusions}

Our results indicated that the aberrant RSFC between the PCC and brain regions sub-serving cognitive control and emotional regulation in patients with MDD. And such functional alterations may have structural basis. These findings may underlie the mechanisms of deficits in cognitive control and emotional regulation of MDD.

\section{Introduction}

Major depressive disorder (MDD), one of the most prevalent mental disorders, is characterized by a lack of interest, low self-worth, feeling of sadness, as well as cognitive and physical symptoms that disturb the normal life and work (Ferrari et al., 2013, Janca and Hiller, 1996). It has brought significant psychological burden for the patients as well as socioeconomic burden for their family and the whole society, and is the largest factor contributing to global disability (Liu et al., 2020). Because the pathogenesis of depression is not yet fully understood, the guideline for treatment mainly depends on clinical observations of depressive symptoms severity (Köhler-Forsberg et al., 2020). With the advancing neuroimaging technology, we can now investigate the neuropathological mechanisms of MDD and identify potential neural biomarkers of MDD that could inform treatment efficacy (Drysdale et al., 2017).

Resting-state functional magnetic resonance imaging (rs-fMRI) is one of the commonly used neuroimaging approaches to examine the brain activation in MDD. Many rs-fMRI studies have showed its validity to explore the neurobiological mechanism of MDD (Iwabuchi et al., 2015, Wang et al., 2019, Zhou et al., 2020). The rs-fMRI has a number of advantages including reproducibility, non-invasiveness and higher sensitivity in detecting illness-related brain functional alterations and structural abnormalities (Fox and Raichle, 2007). Resting-state functional connectivity (RSFC) can measure the properties of intrinsic brain functional networks that can be attributed to clinical variables (Castellanos et al., 2013). Previous studies showed that the aberrant default mode network (DMN) RSFC could be a network-based biological marker for disease mechanism and an indicator for clinical symptoms of MDD (Liu et al., 2018).

The posterior cingulate cortex (PCC), the core region of the DMN, plays a pivotal role in self-referential processing (Greicius et al., 2004, Johnson et al., 2006). One important function of the PCC is the facilitation of the construction of mental models of personally significant events with two subsystems within the DMN, namely the medial temporal lobe (MTL) subsystem and the dorsal medial prefrontal cortex (dmPFC) subsystem (Andrews-Hanna et al., 2010). Empirical studies indicated that the dmPFC subsystem is activated in response to self-relevant mental simulations such as mentalizing scenarios and meta-cognitive processes of reflecting or deducing upon the present mental states of one's self and others (Frith and Frith, 2003), while the MTL subsystem is involved in mnemonic scene construction, an important component process of future thinking (Andrews-Hanna et al., 2010, Hearne et al., 2015, Spalding et al., 2018). Importantly, abnormal RSFC of the PCC have been found to be correlated with remarkable clinical manifestations of depression. Zhu et al. reported that functional connectivity in the PCC and AG areas has a close association with overgeneral autobiographical memory phenomena of MDD patients (Zhu et al., 2012). Berman et al. suggested that connectivity between the subgenual cingulate and the PCC during rest period related strongly to ruminative tendencies (Berman et al., 2011).

Evidence suggests striking differences in PCC connectivity with whole brain between patients with MDD and healthy control subjects (HCs) (Berman et al., 2014, Bluhm et al., 2009, Yang et al., 2016). However, these results are inconsistent across studies. For instance, on the one hand, some studies reported increased RSFC in depressed participants compared with HCs between the seed region of interesting (ROI) at the PCC with several cortical and subcortical midline brain regions, such as bilateral precuneus, anterior cingulate cortex, medial prefrontal cortex (Alexopoulos

Page 2/14 
et al., 2012, Andreescu et al., 2013). On the other hand, some studies reported decreased RSFC of the PCC with the bilateral caudate, thalamus, amygdala and the temporal cortex (Bluhm et al., 2009, Chase et al., 2014). This discrepancy could be attributed to several reasons, such as variations in the definition of the PCC seed, small sample size, subject heterogeneity, and different analytical methods across studies. To address this issue, a quantitative meta-analysis could help identify the most prominent and consistent PCC-based RSFC alterations in MDD by controlling the above-mentioned confounding factors.

The present study aimed to conduct a meta-analysis to unify findings of RSFC studies and identify consistent PCC-based RSFC changes in MDD. In addition, to explore the potential moderators moderating the PCC-based RSFC patterns, we performed a meta-regression analysis through the association between the PCC-based RSFC and the available clinical variables (e.g., depressive symptoms). Anisotropic effect-size version of seedbased d mapping (AES-SDM), a powerful tool based on well-established statistical measures for meta-analytic studies on differences in brain activity (Radua and Mataix-Cols, 2012), was employed in the present study to integrate the results of the PCC-based RSFC abnormalities and delineate between-study heterogeneities. Considering previous observations of PCC-based abnormal RSFC and other cortical and subcortical structures, we hypothesized that: (i) PCC would show consistent abnormal RSFC to the cortical and subcortical regions, and (ii) the identified altered RSFC was might be moderated by clinical variables. Moreover, we also set out to identify the structural basis of functional brain abnormalities by combining voxel-based morphometry (VBM) and RSFC results.

\section{Methods}

\section{Literature search and selection}

A comprehensive literature search was conducted in Web of Science and PubMed for articles up to January 30, 2020, using the keywords "rest*(ing)", "connect*(-ivity)", "depress*(-ion, -ive)" and "posterior cingulate”. The reference section of the studies that fulfilled the inclusion criteria was manually screened to identify additional studies. For the study that the seed ROI or peak effect coordinates were not provided, authors were contacted for this information. Under this strategy, 471 papers were identified in total. The inclusion criteria were as follows: (i) articles were published in peer-reviewed English language journals; (ii) reported group comparison between MDD patients and healthy controls; (iii) examined the whole-brain RSFC of a seed in the PCC; (iv) reported coordinates in a standard stereotaxic space such as Talairach or Montreal Neurological Institute (MNI); and (v) reported rs-fMRI scan results including treatment studies with pretreatment (baseline) assessment. Studies of brain injury or other organic lesion were excluded. The screening procedure for the current meta-analysis was prepared according to Preferred Reporting Items for Systematic Reviews and Meta-Analyses (PRISMA) statements (Moher et al., 2009). The detailed screening protocol is illustrated in Fig. 1.

\section{Quality assessment and data extraction}

To achieve high standard of analysis, we assessed the quality of included studies by using a 12-points checklist containing the demographical and clinical characteristics of subjects as well as methods implemented during the imaging procedure (Li et al., 2020) (see Table S1 in Supplementary). Each point was scored as $0,0.5$ or 1 if the criteria were unfulfilled, partially met or completely met, respectively. All studies that met the inclusion criteria should pass the fractional line of quality assessment set ahead, scoring $>6.0$. Specific information, including the demographic and clinical characteristics (sample size, mean age, gender) and illness-related variables (duration of illness, mean age of first onset, medication status, score of severity) as well as scanning parameters (field strength of scanner, repetition/echo time) were retrieved as the basic data (see Table 1 and Table S2 in Supplementary) and were used to perform quality assessment in accordance with the checklist. A higher score represents a higher quality of original articles. Additionally, the current meta-analysis was based on coordinates showing the locations of significant group differences in RSFC. Therefore, coordinates of the PCC-seed ROI, and the corresponding peak of each significant between-group effects were extracted from each study. Following Kaiser et al., we categorized the disorder related effects into hypo-connectivity or hyperconnectivity in MDD group compared with healthy controls of each study (Kaiser et al., 2015). Hypo-connectivity (i.e., MDD < controls) was defined as reduced positive or increased negative RSFC in MDD versus controls; hyper-connectivity (i.e., MDD > controls) was defined as reduced negative or increased positive RSFC in MDD versus controls. 
Table 1

Demographic characteristics and clinical information of included studies

\begin{tabular}{|c|c|c|c|c|c|c|c|c|c|c|c|}
\hline \multirow[t]{2}{*}{ Studies } & \multicolumn{7}{|c|}{ MDD patients } & \multicolumn{2}{|c|}{$\begin{array}{l}\text { Healthy } \\
\text { controls }\end{array}$} & \multirow{2}{*}{$\begin{array}{l}\text { Seed } \\
\text { location } \\
\text { (space \& } \\
\text { coordinates, } \\
x, y, z \text { ) }\end{array}$} & \multirow{2}{*}{$\begin{array}{l}\text { Quality } \\
\text { score } \\
\text { (out of } \\
12 \text { ) }\end{array}$} \\
\hline & $\begin{array}{l}N \\
(M)\end{array}$ & $\begin{array}{l}\text { Age } \\
\text { (yrs) }\end{array}$ & $\begin{array}{l}\text { Illness } \\
\text { duration } \\
\text { (yrs) }\end{array}$ & $\begin{array}{l}\text { Age } \\
\text { of } \\
\text { first } \\
\text { onset } \\
\text { (yrs) }\end{array}$ & $\begin{array}{l}\text { Antidepressant } \\
\text { naïve, n (\%) }\end{array}$ & $\begin{array}{l}\text { Depression } \\
\text { symptoms } \\
\text { (scale } \\
\text { type) }\end{array}$ & $\begin{array}{l}\text { Comorbid } \\
\text { anxiety, n } \\
(\%)\end{array}$ & $\begin{array}{l}N \\
(M)\end{array}$ & $\begin{array}{l}\text { Age } \\
\text { (yrs) }\end{array}$ & & \\
\hline $\begin{array}{l}\text { Alexopoulos } \\
\text { et al. } 2012\end{array}$ & 32 & 67.90 & NA & NA & $32(100 \%)$ & $\begin{array}{l}25.60 \\
\text { (HAMD- } \\
24) ; 23.55 \\
\text { (MADRS) }\end{array}$ & 0 & 10 & 68.60 & $\begin{array}{l}\text { MNI: -5, -49, } \\
40\end{array}$ & 9 \\
\hline $\begin{array}{l}\text { Andreescu } \\
\text { et al. } 2014\end{array}$ & $\begin{array}{l}47 \\
(13)\end{array}$ & 68.72 & NA & 48.63 & 40 (85.1\%) & $\begin{array}{l}19.06 \\
(\text { HDRS, N } \\
=44)\end{array}$ & 0 & $\begin{array}{l}46 \\
(13)\end{array}$ & 72.89 & $\begin{array}{l}\text { Bilateral } \\
\text { PCC from } \\
\text { the AAL } \\
\text { atlas }\end{array}$ & 11.5 \\
\hline $\begin{array}{l}\text { Berman et } \\
\text { al. } 2011\end{array}$ & $\begin{array}{l}14 \\
(5)\end{array}$ & 25.70 & NA & NA & $9(60 \%)$ & $\begin{array}{l}30.00 \\
(\mathrm{BDI})\end{array}$ & $2(6.25 \%)$ & $\begin{array}{l}15 \\
(5)\end{array}$ & 23.00 & $\begin{array}{l}\text { MNI: -7, -45, } \\
24\end{array}$ & 10 \\
\hline $\begin{array}{l}\text { Bessette et } \\
\text { al. } 2018\end{array}$ & $\begin{array}{l}47 \\
(13)\end{array}$ & 22.16 & NA & 16.61 & 47 (100\%) & $\begin{array}{l}1.64 \\
\text { (HAMD); }\end{array}$ & 0 & $\begin{array}{l}35 \\
(14)\end{array}$ & 21.45 & $\begin{array}{l}\text { MNI: } \pm 5 \\
-50,36\end{array}$ & 11.5 \\
\hline $\begin{array}{l}\text { Bluhm et al. } \\
2009\end{array}$ & $\begin{array}{l}14 \\
(5)\end{array}$ & 21.90 & NA & NA & 13 (92.9\%) & $\begin{array}{l}24.50 \\
(\mathrm{BDI})\end{array}$ & 0 & $\begin{array}{l}15 \\
(4)\end{array}$ & 23.50 & $\begin{array}{l}\text { MNI: 0, -56, } \\
-20\end{array}$ & 9.5 \\
\hline $\begin{array}{l}\text { Chase et al. } \\
2014\end{array}$ & $\begin{array}{l}14 \\
(0)\end{array}$ & 26.40 & NA & NA & $11(78.6 \%)$ & $\begin{array}{l}21.60 \\
\text { (HAMD-25) }\end{array}$ & 0 & $\begin{array}{l}23 \\
(0)\end{array}$ & 27.70 & $\begin{array}{l}\text { Cluster } \\
\text { from } \\
\text { previous } \\
\text { studya }^{a}\end{array}$ & 10 \\
\hline $\begin{array}{l}\text { Cheng et al. } \\
2018\end{array}$ & $\begin{array}{l}336 \\
(216)\end{array}$ & 40.97 & 4.88 & NA & $125(37.2 \%)$ & $\begin{array}{l}18.96 \\
\text { (HAMD-17) }\end{array}$ & 0 & $\begin{array}{l}350 \\
(226)\end{array}$ & 42.26 & $\begin{array}{l}\text { Bilateral } \\
\text { PCC from } \\
\text { the AAL } \\
\text { atlas }\end{array}$ & 11 \\
\hline $\begin{array}{l}\text { Gaffrey et } \\
\text { al. } 2012\end{array}$ & $\begin{array}{l}21 \\
(9)\end{array}$ & 9.50 & NA & NA & $21(100 \%)$ & $\begin{array}{l}45.20(\mathrm{CDI}- \\
\mathrm{C})\end{array}$ & 0 & $\begin{array}{l}18 \\
(9)\end{array}$ & 9.00 & $\begin{array}{l}\text { TAL: }-2,-36 \text {, } \\
37\end{array}$ & 9.5 \\
\hline $\begin{array}{l}\text { Guo et al. } \\
2013\end{array}$ & $\begin{array}{l}24 \\
(13)\end{array}$ & 25.58 & 4.96 & NA & $24(100 \%)$ & $\begin{array}{l}25.75 \\
\text { (HAMD-17) }\end{array}$ & 0 & $\begin{array}{l}24 \\
(14)\end{array}$ & 24.04 & $\begin{array}{l}\text { Bilateral } \\
\text { PCC } \\
\text { showing } \\
\text { group } \\
\text { difference }\end{array}$ & 9 \\
\hline $\begin{array}{l}\text { Jacobs et } \\
\text { al. } 2016\end{array}$ & $\begin{array}{l}51 \\
(15)\end{array}$ & 21.06 & NA & 15.53 & $51(100 \%)$ & $\begin{array}{l}2.35 \\
\text { (HAMD) }\end{array}$ & $\begin{array}{l}27 \\
(52.9 \%)\end{array}$ & $\begin{array}{l}26 \\
(12)\end{array}$ & 21.15 & $\begin{array}{l}\text { MNI: -5, -50, } \\
36\end{array}$ & 10 \\
\hline $\begin{array}{l}\text { Kim et al. } \\
2015\end{array}$ & $\begin{array}{l}22 \\
(14)\end{array}$ & 13.90 & NA & NA & $22(100 \%)$ & $\begin{array}{l}40.00 \\
(\mathrm{CDI})\end{array}$ & 0 & $\begin{array}{l}20 \\
(14)\end{array}$ & 14.50 & $\begin{array}{l}\text { Bilateral } \\
\text { PCC from } \\
\text { AAL }\end{array}$ & 11.5 \\
\hline $\begin{array}{l}\text { Liu et al. } \\
2018\end{array}$ & $\begin{array}{l}27 \\
(10)\end{array}$ & 67.33 & NA & NA & $27(100 \%)$ & $\begin{array}{l}31.78 \\
\text { (HAMD-17) }\end{array}$ & 0 & $\begin{array}{l}40 \\
(18)\end{array}$ & 64.68 & $\begin{array}{l}\text { MNI: } 0,-53 \\
26\end{array}$ & 9.5 \\
\hline \multirow[t]{2}{*}{$\begin{array}{l}\text { Peters et al. } \\
2016\end{array}$} & $\begin{array}{l}23 \\
(10)\end{array}$ & 15.61 & NA & NA & $11(47.8 \%)$ & $\begin{array}{l}60.48 \\
\text { (RADS); }\end{array}$ & $8(35.0 \%)$ & $\begin{array}{l}10 \\
(3)\end{array}$ & 15.80 & $\begin{array}{l}\text { MNI: }-5,-50 \text {, } \\
36\end{array}$ & 10 \\
\hline & & & & & & $\begin{array}{l}26.96 \\
\text { (CDRS-R); }\end{array}$ & & & & & \\
\hline $\begin{array}{l}\text { Renner et al. } \\
2016\end{array}$ & $\begin{array}{l}18 \\
(13)\end{array}$ & 41.17 & NA & NA & $8(44.4 \%)$ & $\begin{array}{l}30.50 \\
(\mathrm{BDI})\end{array}$ & 0 & $\begin{array}{l}18 \\
(13)\end{array}$ & 42.67 & $\begin{array}{l}\text { MNI: -9, -56, } \\
25\end{array}$ & 10 \\
\hline $\begin{array}{l}\text { Satyshur et } \\
\text { al. } 2018\end{array}$ & $\begin{array}{l}33 \\
(0)\end{array}$ & 30.61 & NA & NA & 33 100\%) & $\begin{array}{l}34.85 \text { (IDS- } \\
\text { C) }\end{array}$ & 0 & $\begin{array}{l}50 \\
(0)\end{array}$ & 35.66 & $\begin{array}{l}\text { Bilateral } \\
\text { PCC from } \\
\text { HOA }\end{array}$ & 10.5 \\
\hline
\end{tabular}

Note: MDD, major depressive disorder; HAM-D, Hamilton Rating Scale for Depression; BDI, Beck Depression Inventory (second edition); MADRS, Montgomery Asberg Depression Rating Scale; IDS-C, Inventory of Depressive Symptomatology-Clinician Rated; RRS, Ruminative Response Scale; RADS, Reynold Adolescent Depression Scale; CDI, Children's Depression Inventory; MNI, Montreal Neurologic Institute; TAL, Talairach; AAL: Automated Anatomical Labeling; HOA: Harvard-Oxford Atlas; NA, not applicable. ${ }^{\text {a }}$ Connectivity-based parcellation of human cingulate cortex and its relation to functional specialization (Beckmann, Johansen-Berg, \& Rushworth, 2009). 


\begin{tabular}{|c|c|c|c|c|c|c|c|c|c|c|c|}
\hline \multirow[t]{3}{*}{ Studies } & \multicolumn{7}{|c|}{ MDD patients } & \multicolumn{2}{|c|}{$\begin{array}{l}\text { Healthy } \\
\text { controls }\end{array}$} & \multirow{3}{*}{$\begin{array}{l}\text { Seed } \\
\text { location } \\
\text { (space \& } \\
\text { coordinates, } \\
x, y, z)\end{array}$} & \multirow{3}{*}{$\begin{array}{l}\text { Quality } \\
\text { score } \\
\text { (out of } \\
\text { 12) }\end{array}$} \\
\hline & $\begin{array}{l}\mathrm{N} \\
(\mathrm{M})\end{array}$ & $\begin{array}{l}\text { Age } \\
\text { (yrs) }\end{array}$ & $\begin{array}{l}\text { Illness } \\
\text { duration } \\
\text { (yrs) }\end{array}$ & $\begin{array}{l}\text { Age } \\
\text { of } \\
\text { first } \\
\text { onset }\end{array}$ & $\begin{array}{l}\text { Antidepressant } \\
\text { naïve, n (\%) }\end{array}$ & $\begin{array}{l}\text { Depression } \\
\text { symptoms } \\
\text { (scale } \\
\text { type) }\end{array}$ & $\begin{array}{l}\text { Comorbid } \\
\text { anxiety, n } \\
(\%)\end{array}$ & $\begin{array}{l}N \\
(M)\end{array}$ & $\begin{array}{l}\text { Age } \\
\text { (yrs) }\end{array}$ & & \\
\hline & & & & (yrs) & & & & & & & \\
\hline $\begin{array}{l}\text { Wang et al. } \\
2012\end{array}$ & $\begin{array}{l}35 \\
(9)\end{array}$ & 68.18 & NA & NA & $0(0 \%)$ & $\begin{array}{l}1.15 \\
\text { (HDRS) }\end{array}$ & 0 & $\begin{array}{l}24 \\
(13)\end{array}$ & $71.44 ?$ & $\begin{array}{l}\text { MNI: }-5,-49 \\
40\end{array}$ & 10 \\
\hline $\begin{array}{l}\text { Zhang et al. } \\
2015\end{array}$ & $\begin{array}{l}45 \\
(7)\end{array}$ & 45.38 & NA & NA & $45(100 \%)$ & $\begin{array}{l}27.25 \\
\text { (HAMD-24) }\end{array}$ & 0 & $\begin{array}{l}20 \\
(3)\end{array}$ & 47.75 & $\begin{array}{l}\text { TAL: }-5,-49 \text {, } \\
40\end{array}$ & 10.5 \\
\hline \multicolumn{12}{|c|}{$\begin{array}{l}\text { Note: MDD, major depressive disorder; HAM-D, Hamilton Rating Scale for Depression; BDI, Beck Depression Inventory (second edition); MADRS, } \\
\text { Montgomery Asberg Depression Rating Scale; IDS-C, Inventory of Depressive Symptomatology-Clinician Rated; RRS, Ruminative Response } \\
\text { Scale; RADS, Reynold Adolescent Depression Scale; CDI, Children's Depression Inventory; MNI, Montreal Neurologic Institute; TAL, Talairach; } \\
\text { AAL: Automated Anatomical Labeling; HOA: Harvard-Oxford Atlas; NA, not applicable. a Connectivity-based parcellation of human cingulate } \\
\text { cortex and its relation to functional specialization (Beckmann, Johansen-Berg, \& Rushworth, 2009). }\end{array}$} \\
\hline
\end{tabular}

\section{SDM meta-analysis}

AES-SDM (version 6.12, http://www.sdmproject.com) was employed in a coordinate-based meta-analysis. According to the guidelines of AESSDM, we retrieved the reported peak coordinates and their corresponding $t$ values and saved them into a text file (Radua et al., 2014). All $z$ values were straightforwardly transformed into $t$ values for data analysis using the SDM online converter. In case of studies not reporting any measure related to effect size ( $t$ score, $z$ score, $p$ value, etc), " $n$ " for hypo-connectivity or " $p$ " for hyper-connectivity was written for the SDM software to conduct a pre-analysis to provide an effect size for these peaks. Data extracted from the 17 studies also included sample sizes (for both MDD and HC groups), software package for data analyses (FSL, SPM, or other), and coordinate space (Talairach or MNI space). The $t$-value of each peak was then calculated and converted to Hedges' $\mathrm{g}$, a measure of standardized mean difference appropriate for small sample sizes (Emch et al., 2019). Once the datasets were prepared, a mean effect-size brain map was recreated in the preprocessing of the present meta-analysis, combing the data of each original study and demonstrating both negative and positive differences in the same map. The map was restricted in brain grey matter with a setting of anisotropy $=1$, isotropic full-width at half-maximum (FWHM) $=20 \mathrm{~mm}$, and $p=0.005$.

\section{Voxel-based morphology analysis (VBM) analysis}

To compare the structural differences between MDD patients and controls, AES-SDM was also used in combination with Sleuth software (version 3.0.4, http://www.brainmap.org/sleuth/) for the VBM analyses. Search selections were performed in the VBM database to filter articles which: (i) included patients diagnosed with MDD; (ii) reported gray matter as experiments contrast; and (iii) reported MRI as imaging modality. To further determine qualification, studies were excluded if they: (i) had no typical control group; (ii) included MDD patients with comorbid conditions; and (iii) reported no group comparison between MDD patients and healthy controls. After that, the qualified focis were exported in form of $\mathrm{MNI}$ coordinates and pooled to conduct a meta-analysis of VBM. Results were thresholded using FWHM $=20 \mathrm{~mm}, p=0.005$ and cluster extent $=10$ voxels. To examine the association between functional and structural differences, the regions with abnormal gray matter density or RSFC were then overlaid on the same template.

\section{Sensitivity analyses}

To test the robustness of the main results, we conducted Jackknife sensitivity analysis or "leave-one-out cross validation" (LOOCV) analysis which consists of repeating the mean analysis by systematically excluding a different study each time and repeating the analysis (Radua and MataixCols, 2009). If a previously significant brain region remains significant in most or even all of the LOOCV analyses, it can be concluded that this result has a high replicability (Duko et al., 2020). Any result presenting voxel threshold $p<0.005$ with a peak $Z>1$ and cluster extent $>10$ voxels was regarded to have significantly elevated heterogeneity. Meanwhile, the Jackknife sensitivity of the subgroup meta-analysis was also assessed by discarding 3 studies with comorbid anxiety participants.

\section{Meta-regression}

Meta-regression, a kind of linear model analyses, was applied to explore potential sources of heterogeneity among studies. Variables explored by regression were the depressive symptom severity (the score of the Hamilton Rating Scale for Depression (HAMD)) of MDD patients and percentage of medication-naïve patients. According to the recommendation that meta-regression requires at least 9 studies (Radua and MataixCols, 2009), we excluded the following variables: mean age of first onset, illness duration, and score of severity taped except HAMD. A stringent voxel threshold of $p<0.005$, a peak of $Z>1$ and a cluster extent threshold of 10 voxels were applied to minimize the risk of false-positive findings. In our result, the regression line (meta-regression SDM slope) was presented as a straight line and the SDM value was derived from the proportion of studies that reported RSFC changes near the voxel, representing the difference of RSFC strength between MDD patients and HCs. 


\section{Results}

\section{Included studies and sample characteristics}

Seventeen studies met the inclusion criteria of the present study, with a total of 804 MDD patients and 724 healthy individuals. One of the studies did not report the sex ratio of participants. Furthermore, 5 studies recruited drug-naïve patients, while 1 study included off medication but previously treated patient, and 8 studies reported samples combining off-medication and drug-naïve patients. Notably, the minimum time off medication of patients in the included studies was at least 2 weeks ( 2 weeks, 2 studies; 3 months, 1 study; 6 months, 1 study) according to the four studies that reported the duration of the medication-free period prior to the scan (Jacobs et al., 2016, Liu et al., 2018, Satyshur et al., 2018, Zhang et al., 2015). All of these patients were also defined as "drug-naïve" in the present study. Ultimately, this meta-analysis incorporated 83 peak coordinates extracted from all the included studies, 50 of which reported increased PCC-based RSFC in patients versus healthy controls and 33 revealed decreased RSFC. The mean quality score of these studies was 10.2 (total score was 12), indicating high quality. The detailed demographic and clinical characteristics of included studies and methodological details are listed Tables 1 and TableS2 in Supplementary.

\section{Aberrant PCC-based functional connectivity in MDD}

By pooling all 50 foci labeled as enhanced RSFC in patients with MDD versus controls, we found the following clusters showing significantly and consistently increased RSFC with the PCC, including the left temporal pole (MNI: $-32,0,-26 ; 526$ voxels), the right middle frontal gyrus (MFG, 28, 10, 54; 207 voxels) and the left middle temporal gyrus (MTG, 56, -58, 4; 40 voxels) (see Fig. 2 and Table 2).

Table 2

Differences in functional connectivity in patients with major depressive disorder (MDD) compared with controls.

\begin{tabular}{|c|c|c|c|c|c|c|c|}
\hline \multirow[t]{2}{*}{ Region } & \multicolumn{3}{|c|}{ MNI coordinate } & \multirow[t]{2}{*}{$Z$ value } & \multirow[t]{2}{*}{$\mathbf{P}$} & \multirow[t]{2}{*}{ Voxels No. } & \multirow[t]{2}{*}{ Jackknife sensitivity } \\
\hline & $x$ & $y$ & $\boldsymbol{z}$ & & & & \\
\hline \multicolumn{8}{|l|}{$M D D>H C$} \\
\hline Left temporal pole, middle temporal gyrus (BA 21) & -32 & 0 & -26 & 4.430 & $<0.001$ & 526 & 15 of 17 \\
\hline Right middle frontal gyrus (BA 8) & 28 & 10 & 54 & 5.630 & $<0.001$ & 207 & 17 of 17 \\
\hline Left middle temporal gyrus (BA 37) & -56 & -58 & 4 & 3.449 & $<0.001$ & 40 & 16 of 17 \\
\hline \multicolumn{8}{|l|}{$M D D<H C$} \\
\hline Left dorsolateral superior frontal gyrus (BA 10) & -22 & 66 & 4 & -4.445 & $<0.001$ & 133 & 16 of 17 \\
\hline Left precuneus (BA 30) & 2 & -56 & 10 & -3.538 & $<0.001$ & 37 & 14 of 17 \\
\hline Right precuneus (BA 23) & 6 & -50 & 26 & -3.331 & $<0.001$ & 12 & 4 of 17 \\
\hline
\end{tabular}

Note: BA, Brodmann's area; MNI, Montreal Neurological Institute, voxel size $2 \times 2 \times 2 \mathrm{~mm}^{3}$

Meanwhile, reduced RSFC with the PCC was found in the left superior frontal gyrus (SFG, $-22,66,4,133$ voxels), the left precuneus (PCUN, 2, -56, 10,37 voxels) and the right precuneus $(6,-50,26,12$ voxels) by pooling other 33 foci in the meta-analysis.

\section{VBM results and association between functional and structural alterations in MDD}

By using Sleuth, 45 papers with 144 experiments were identified. After filtering these articles with exclusion criteria, 38 studies with 447 focis were included in the present VBM study. Patients with MDD exhibited consistently decreased gray mater density mainly in the right inferior frontal gyrus extending to the insular cortex compared with healthy controls (Fig. 3b). In contrast, the region that showed significant increased gray mater density was in the right cuneus cortex (see Fig. $3 \mathrm{~b}$ and Table S3 in supplementary). Importantly, the left middle frontal gyrus and the left middle temporal gyrus consistently overlapped in the VBM results and the functional connectivity alterations in MDD (see Fig. 3c).

\section{Sensitivity test for the main finding}

Jackknife sensitivity analysis was conducted to test the robustness of the results. Table 3 lists the increased RSFC in the patients with PCC-seed in the right middle frontal gyrus across all studies, indicating a good reproducibility of these outcomes. Meanwhile, hypoconnectivity between the PCC and the left SFG remained significant in all but one combination of 17 datasets. The left middle temporal gyrus was stable hypoconnected with the PCC in MDD patients, which were preserved in 15/17 of datasets. The result in the left precuneus remained significant in all but three combinations. Of note, hypoconnectivity between the PCC and the right precuneus failed to emerge in most of the study combinations (13 of 17), indicating that this result lacks sufficient robustness and is required to be ruled out in discussion (see Table 3 and Table S4 in supplementary). 
Additionally, the Jackknife sensitivity of the subgroup meta-analysis in studies with non-comorbid anxiety patients also showed high replicability in those regions (see Table S5 in supplementary).

\section{Meta-regression}

The HAMD score of patients was found to be negatively correlated with the extent RSFC changes between the right middle frontal gyrus and the PCC (Fig. 4a). In addition, the extent of RSFC changes between PCC and the right supplementary motor area (SMA) is associated with the percentage of drug-naïve of MDD patients of included studies (Fig. 4b).

\section{Discussion}

The current meta-analysis reviewed 17 studies reporting whole-brain RSFC of the PCC seed and revealed the altered RSFC of the PCC in MDD compared with controls. Specifically, we identified significant elevated RSFC of the PCC with the left middle temporal gyrus extending to the left inferior temporal gyrus as well as the right middle frontal gyrus in MDD. In addition, the PCC exhibited reduced RSFC with the left SFG and left precuneus. Furthermore, regions with aberrant connectivity had a partial overlap with regions that showed decreased gray matter density, namely the left middle temporal gyrus as well as the left middle frontal gyrus. These results remained largely unchanged in the whole-brain Jackknife sensitivity analysis.

\section{Increased RSFC between MTG and PCC in depression}

Hyperconnectivity was found in individuals with MDD between the PCC and left middle temporal gyrus, which is an essential part of the dorsal attention system. The MTG is closely related to the successful decision making in the presence of a stimulus conflict and involved in emotional processing, selective attention and working memory (Corbetta and Shulman, 2002, Fox et al., 2006). Gaffrey et al. (2012) suggested that children with a history of preschool depression demonstrated increased RSFC between the MTG and PCC and such altered RSFC was associated with clinically relevant behavior such as decreased use of proactive emotion regulation strategies. Also, emerging evidence has indicated that abnormal MTG-DMN RSFC may contribute to negative thinking mode and pessimistic emotional experience in MDD patients, triggering self-referential processing and rumination (Ma et al., 2012). Thus, the current meta-analysis provides further evidence to support the involvement of the PCC and MTG in the underlying pathophysiology of MDD.

\section{Altered RSFC between the dIPFC and PCC in depression}

Compared with controls, the RSFC strength increased between the PCC and right middle frontal gyrus, and decreased between the PCC and left SFG in MDD. The SFG and middle frontal gyrus are the sub-regions of the dorsolateral prefrontal cortex (dIPFC), which is a core part of the cognitive control network (CCN). The CCN participates in a variety of executive functions, such as response inhibition, working memory and emotional regulation (Habas et al., 2009, Levy and Goldman-Rakic, 2000, Zhang et al., 2017). It is worth noting that, the SFG is critical for mental manipulation and monitoring information within higher levels of working memory processing (du Boisgueheneuc et al., 2006, Petrides, 2000). Evidence from neuroimaging studies suggested that the $\mathrm{CCN}$ is linked to memory impairment and attentional bias experienced by depressed patients (Rogers et al., 2004, Sheline et al., 2010). Hence, the failure of control and regulation from the CCN to the PCC may result in impaired cognitive control over negative emotions, ability to synthesize memories, decision making observed in depression.

The current study also found an increased RSFC between the PCC and the middle frontal gyrus in patients. The middle frontal gyrus is involved in bottom-up/stimulus-driven orienting of attention and usually has an antagonistic relationship with the DMN and the attentional control originated from the middle frontal gyrus helps to regulate the DMN activity (Fox et al., 2006, Kucyi et al., 2012). In our previous work, we have suggested that the enhanced RSFC between prefrontal cortex and DMN could be an adaptive process in response to disorder, and then it is conceivable that the adaption process is signaled by depression symptom severity (Zhang et al., 2020). It is in line with our finding of meta-regression that the extent of RSFC changes between PCC and MFG is negatively correlated with the HAMD score of depressed patients. Hence, this may help explain why depressed patients are able to control over depressive symptoms such as rumination and negative internalizing states during remitted period (Jacobs et al., 2016).

\section{Decreased RSFC between the PCUN and PCC in depression}

The present study also revealed hypoconnectivity in MDD between the PCC and left precuneus, an important sub-region of the DMN. Precuneus plays an important role in cause-and-effect judgements, which may lead to the self-referential processing ruminations (Jones and Bhattacharya, 2014, Lai, 2018). As suggested in a previous study, the connection between the precuneus and PCC was involved in self-relevant cognitive activities, such as the self-reflection and the maintenance of a sense of self-consciousness (Fransson and Marrelec, 2008). In line with our finding of decreased PCC-precuneus RSFC in patients with MDD, another fMRI study also reported decreased RSFC of the PCC-precuneus in the late-onset depression group (Liu et al., 2018) and such alteration can be interpreted as reflecting failure to attenuate self-referential activity to a situationally appropriate manner in depression (Sheline et al., 2009).

Correlations between functional and structural abnormalities 
Using VBM and RSFC analyses, brain functional and structural alterations were observed in MDD. Regions with altered RSFC had a significant overlap with regions that revealed decreased gray matter density, which were mainly located in the left MTG as well as the left MFG. Generally speaking, structural deficits may represent more stable and long-standing changes, while functional alterations measured by fMRI related to acute illness stage and were more sensitive to drug utilization (Ren et al., 2013), which could be a possible explanation for those regions that only exhibited RSFC deficits. Hence, it is suggested that the left MTG and the left MFG may be crucial to the underlying pathological mechanism of MDD, but future investigations are still needed to further confirm.

\section{Limitations}

Several limitations should be acknowledged in this study. First, the statistical analytic methods implemented in the included studies were limited to seed-based RSFC for the current meta-analysis, without using ICA or seed-derived network studies. Such strict strategy may cause certain omission but indeed provide a clear presentation of the altered connectivity pattern of the PCC. Second, potential modulators may affect changes in the strength of RSFC, such as age, treatment history. Thus, with the exploratory analysis, we identified that the change of RSFC was significantly correlated with the proportion of treatment. However, due to the limited number of included studies, the clinical value of the change of the connection strength between SMA and PCC merit future investigations. Third, meta-regression of age-related differences in MDD patients were not perform due to inadequate empirical data, despite of the wide age range in the included studies. Even though meta-regression analysis revealed a significant association between age and the aberrant PCC-based RSFC, the potential impact of age on human brain's RSFC is remained to be explored. Fourthly, the studies we included were cross-sectional, so the inference of a causal link between the brain dysfunction and clinical features still require more valid supportive evidence. Lastly, the size and location inconsistency of the seed ROI definitions were observed among the included studies, which may limit the accuracy of our results. Future investigations such as overlap rate analysis on the PCC seed definitions will be necessary to more fully address this question.

\section{Conclusion}

The present meta-analysis identified significant and consistent PCC seed-to-whole-brain RSFC alterations in MDD, including hyperconnectivity of the PCC with the middle temporal gyrus and the middle frontal gyrus and hypoconnectivity with the superior frontal gyrus and the precuneus. And such functional alterations may have structural basis, especially in the left middle temporal gyrus and the left middle frontal gyrus. These functional abnormalities suggested the disrupted executive control in MDD, which may account for the core symptom of rumination. The findings may shed light on the neuropathology mechanisms of depression.

\section{Declarations}

Acknowledgements This study was supported by Nature Science Foundation of China (ref: 31900806). The funding organizations played no further role in study design, data collection, analysis and interpretation, and paper writing.

Author contributions The study concepts, study design and integrity of the entire study are guaranteed by ZZ, RZ; RZ designed the study, ZZ researched the literature, extracted and analyzed the data. $\mathrm{WL}, \mathrm{ML}$, and RZ wrote the manuscript. $\mathrm{YW}, \mathrm{XW}, \mathrm{YL}$ and $\mathrm{RH}$ edited and revised the manuscript.

Funding This study was funded by Nature Science Foundation of China (ref: 31900806).

Conflict of interest The authors declare that they have no competing interests.

Ethical approval The article does not contain any studies with human participants or animals perform by any of the authors.

Consent to Participate: Not applicable.

Consent to Publish: Agree.

Availability of data and materials: Data and code will be made available on request.

\section{References}

1. Alexopoulos, G. S., Hoptman, M. J., Kanellopoulos, D., Murphy, C. F., Lim, K. O., \& Gunning, F. M. (2012). Functional connectivity in the cognitive control network and the default mode network in late-life depression. J Affect Disord, 139, 56-65. https://doi.org/10.1016/j.jad.2011.12.002

2. Andreescu, C., Tudorascu, D. L., Butters, M. A., Tamburo, E., Patel, M., Price, J. ... Aizenstein, H., 3rd \&. (2013). Resting state functional connectivity and treatment response in late-life depression. Psychiatry Res, 214, 313-321. https://doi.org/10.1016/j.pscychresns.2013.08.007

3. Andrews-Hanna, J. R., Reidler, J. S., Sepulcre, J., Poulin, R., \& Buckner, R. L. (2010). Functional-anatomic fractionation of the brain's default network. Neuron, 65, 550-562. https://doi.org/10.1016/j.neuron.2010.02.005 
4. Berman, M. G., Misic, B., Buschkuehl, M., Kross, E., Deldin, P. J., Peltier, S. ... Jonides, J. (2014). Does resting-state connectivity reflect depressive rumination? A tale of two analyses. Neuroimage, 103, 267-279. https://doi.org/10.1016/j.neuroimage.2014.09.027

5. Berman, M. G., Peltier, S., Nee, D. E., Kross, E., Deldin, P. J., \& Jonides, J. (2011). Depression, rumination and the default network. Soc Cogn Affect Neurosci, 6, 548-555. https://doi.org/10.1093/scan/nsq080

6. Bluhm, R., Williamson, P., Lanius, R., Théberge, J., Densmore, M., Bartha, R. ... Osuch, E. (2009). Resting state default-mode network connectivity in early depression using a seed region-of-interest analysis: decreased connectivity with caudate nucleus. Psychiatry Clin Neurosci, 63, 754-761. https://doi.org/10.1111/j.1440-1819.2009.02030.x

7. Castellanos, F. X., Di Martino, A., Craddock, R. C., Mehta, A. D., \& Milham, M. P. (2013). Clinical applications of the functional connectome. Neuroimage. 80, 527 - 40 https://doi.org/10.1016/j.neuroimage.2013.04.083

8. Chase, H. W., Moses-Kolko, E. L., Zevallos, C., Wisner, K. L., \& Phillips, M. L. (2014). Disrupted posterior cingulate-amygdala connectivity in postpartum depressed women as measured with resting BOLD fMRI. Soc Cogn Affect Neurosci, 9, 1069-1075.

https://doi.org/10.1093/scan/nst083

9. Corbetta, M., \& Shulman, G. L. (2002). Control of goal-directed and stimulus-driven attention in the brain. Nat Rev Neurosci, 3, $201-215$. https://doi.org/10.1038/nrn755

10. Drysdale, A. T., Grosenick, L., Downar, J., Dunlop, K., Mansouri, F., Meng, Y. ... Liston, C. (2017). Resting-state connectivity biomarkers define neurophysiological subtypes of depression. Nat Med, 23, 28-38. https://doi.org/10.1038/nm.4246

11. du Boisgueheneuc, F., Levy, R., Volle, E., Seassau, M., Duffau, H., Kinkingnehun, S. ... Dubois, B. (2006). Functions of the left superior frontal gyrus in humans: a lesion study. Brain, 129, 3315-3328. https://doi.org/10.1093/brain/awl244

12. Duko, B., Ayano, G., Pereira, G., Betts, K., \& Alati, R. (2020). Prenatal tobacco use and the risk of mood disorders in offspring: a systematic review and meta-analysis. Soc Psychiatry Psychiatr Epidemiol, 55, 1549-1562. https://doi.org/10.1007/s00127-020-01949-y

13. Emch, M., von Bastian, C. C., \& Koch, K. (2019). Neural Correlates of Verbal Working Memory: An fMRI Meta-Analysis. Front Hum Neurosci, 13, 180. https://doi.org/10.3389/fnhum.2019.00180

14. Ferrari, A. J., Charlson, F. J., Norman, R. E., Patten, S. B., Freedman, G., Murray, C. J. ... Whiteford, H. A. (2013). Burden of depressive disorders by country, sex, age, and year: findings from the global burden of disease study 2010. PLoS Med, 10, e1001547. https://doi.org/10.1371/journal.pmed.1001547

15. Fox, M. D., Corbetta, M., Snyder, A. Z., Vincent, J. L., \& Raichle, M. E. (2006). Spontaneous neuronal activity distinguishes human dorsal and ventral attention systems. Proc Natl Acad Sci U S A, 103, 10046-10051. https://doi.org/10.1073/pnas.0604187103

16. Fox, M. D., \& Raichle, M. E. (2007). Spontaneous fluctuations in brain activity observed with functional magnetic resonance imaging. Nat Rev Neurosci, 8, 700-711. https://doi.org/10.1038/nrn2201

17. Fransson, P., \& Marrelec, G. (2008). The precuneus/posterior cingulate cortex plays a pivotal role in the default mode network: Evidence from a partial correlation network analysis. Neuroimage, 42, 1178-1184. https://doi.org/10.1016/j.neuroimage.2008.05.059

18. Frith, U., \& Frith, C. D. (2003). Development and neurophysiology of mentalizing. Philos Trans R Soc Lond B Biol Sci, 358, $459-473$. https://doi.org/10.1098/rstb.2002.1218

19. Gaffrey, M. S., Luby, J. L., Botteron, K., Repovš, G., \& Barch, D. M. (2012). Default mode network connectivity in children with a history of preschool onset depression. J Child Psychol Psychiatry, 53, 964-972. https://doi.org/10.1111/j.1469-7610.2012.02552.x

20. Greicius, M. D., Srivastava, G., Reiss, A. L., \& Menon, V. (2004). Default-mode network activity distinguishes Alzheimer's disease from healthy aging: evidence from functional MRI. Proc Natl Acad Sci U S A, 101, 4637-4642. https://doi.org/10.1073/pnas.0308627101

21. Habas, C., Kamdar, N., Nguyen, D., Prater, K., Beckmann, C. F., Menon, V., \& Greicius, M. D. (2009). Distinct cerebellar contributions to intrinsic connectivity networks. J Neurosci, 29, 8586-8594. https://doi.org/10.1523/jneurosci.1868-09.2009

22. Hearne, L., Cocchi, L., Zalesky, A., \& Mattingley, J. B. (2015). Interactions between default mode and control networks as a function of increasing cognitive reasoning complexity. Hum Brain Mapp, 36, 2719-2731. https://doi.org/10.1002/hbm.22802

23. Iwabuchi, S. J., Krishnadas, R., Li, C., Auer, D. P., Radua, J., \& Palaniyappan, L. (2015). Localized connectivity in depression: a meta-analysis of resting state functional imaging studies. Neurosci Biobehav Rev, 51, 77-86. https://doi.org/10.1016/j.neubiorev.2015.01.006

24. Jacobs, R. H., Barba, A., Gowins, J. R., Klumpp, H., Jenkins, L. M., Mickey, B. J. ... Langenecker, S. A. (2016). Decoupling of the amygdala to other salience network regions in adolescent-onset recurrent major depressive disorder. Psychol Med, 46, 1055-1067. https://doi.org/10.1017/s0033291715002615

25. Janca, A., \& Hiller, W. (1996). ICD-10 checklists-a tool for clinicians' use of the ICD-10 classification of mental and behavioral disorders. Compr Psychiatry, 37, 180-187. https://doi.org/10.1016/s0010-440x(96)90034-6

26. Johnson, M. K., Raye, C. L., Mitchell, K. J., Touryan, S. R., Greene, E. J., \& Nolen-Hoeksema, S. (2006). Dissociating medial frontal and posterior cingulate activity during self-reflection. Soc Cogn Affect Neurosci, 1, 56-64. https://doi.org/10.1093/scan/nsl004

27. Jones, R., \& Bhattacharya, J. (2014). A role for the precuneus in thought-action fusion: evidence from participants with significant obsessivecompulsive symptoms. Neuroimage Clin, 4, 112-121. https://doi.org/10.1016/j.nicl.2013.11.008

Page 9/14 
28. Kaiser, R. H., Andrews-Hanna, J. R., Wager, T. D., \& Pizzagalli, D. A. (2015). Large-Scale Network Dysfunction in Major Depressive Disorder: A Meta-analysis of Resting-State Functional Connectivity. JAMA Psychiatry, 72, 603-611. https://doi.org/10.1001/jamapsychiatry.2015.0071

29. Köhler-Forsberg, K., Jorgensen, A., Dam, V. H., Stenbæk, D. S., Fisher, P. M., Ip, C. T. ... Frokjaer, V. G. (2020). Predicting Treatment Outcome in Major Depressive Disorder Using Serotonin 4 Receptor PET Brain Imaging, Functional MRI, Cognitive-, EEG-Based, and Peripheral Biomarkers: A NeuroPharm Open Label Clinical Trial Protocol. Front Psychiatry, 11, 641. https://doi.org/10.3389/fpsyt.2020.00641

30. Kucyi, A., Moayedi, M., Weissman-Fogel, I., Hodaie, M., \& Davis, K. D. (2012). Hemispheric asymmetry in white matter connectivity of the temporoparietal junction with the insula and prefrontal cortex. PLoS One, 7, e35589. https://doi.org/10.1371/journal.pone.0035589

31. Lai, C. H. (2018). The regional homogeneity of cingulate-precuneus regions: The putative biomarker for depression and anxiety. J Affect Disord, 229, 171-176. https://doi.org/10.1016/j.jad.2017.12.086

32. Levy, R., \& Goldman-Rakic, P. S. (2000). Segregation of working memory functions within the dorsolateral prefrontal cortex. Exp Brain Res, 133, 23-32. https://doi.org/10.1007/s002210000397

33. Li, Q., Zhao, Y., Chen, Z., Long, J., Dai, J., Huang, X. ... Gong, Q. (2020). Meta-analysis of cortical thickness abnormalities in medication-free patients with major depressive disorder. Neuropsychopharmacology, 45, 703-712. https://doi.org/10.1038/s41386-019-0563-9

34. Liu, Q., He, H., Yang, J., Feng, X., Zhao, F., \& Lyu, J. (2020). Changes in the global burden of depression from 1990 to 2017 : Findings from the Global Burden of Disease study. J Psychiatr Res, 126, 134-140. https://doi.org/10.1016/j.jpsychires.2019.08.002

35. Liu, R., Yue, Y., Hou, Z., Yuan, Y., \& Wang, Q. (2018). Risk factors associated with cognitions for late-onset depression based on anterior and posterior default mode sub-networks. J Affect Disord, 235, 544-550. https://doi.org/10.1016/j.jad.2018.04.065

36. Ma, C., Ding, J., Li, J., Guo, W., Long, Z., Liu, F. ... Chen, H. (2012). Resting-state functional connectivity bias of middle temporal gyrus and caudate with altered gray matter volume in major depression. PLoS One, 7, e45263. https://doi.org/10.1371/journal.pone.0045263

37. Moher, D., Liberati, A., Tetzlaff, J., \& Altman, D. G. (2009). Preferred reporting items for systematic reviews and meta-analyses: the PRISMA statement. PLoS Med, 6, e1000097. https://doi.org/10.1371/journal.pmed.1000097

38. Petrides, M. (2000). The role of the mid-dorsolateral prefrontal cortex in working memory. Exp Brain Res, 133, 44-54. https://doi.org/10.1007/s002210000399

39. Radua, J., \& Mataix-Cols, D. (2009). Voxel-wise meta-analysis of grey matter changes in obsessive-compulsive disorder. Br J Psychiatry, 195, 393-402. https://doi.org/10.1192/bjp.bp.108.055046

40. Radua, J., \& Mataix-Cols, D. (2012). Meta-analytic methods for neuroimaging data explained. Biol Mood Anxiety Disord, 2, 6. https://doi.org/10.1186/2045-5380-2-6

41. Radua, J., Rubia, K., Canales-Rodríguez, E. J., Pomarol-Clotet, E., Fusar-Poli, P., \& Mataix-Cols, D. (2014). Anisotropic kernels for coordinatebased meta-analyses of neuroimaging studies. Front Psychiatry, 5, 13. https://doi.org/10.3389/fpsyt.2014.00013

42. Ren, W., Lui, S., Deng, W., Li, F., Li, M., Huang, X. ... Gong, Q. (2013). Anatomical and functional brain abnormalities in drug-naive first-episode schizophrenia. Am J Psychiatry, 170, 1308-1316. https://doi.org/10.1176/appi.ajp.2013.12091148

43. Rogers, M. A., Kasai, K., Koji, M., Fukuda, R., Iwanami, A., Nakagome, K. ... Kato, N. (2004). Executive and prefrontal dysfunction in unipolar depression: a review of neuropsychological and imaging evidence. Neurosci Res, 50, 1-11. https://doi.org/10.1016/j.neures.2004.05.003

44. Satyshur, M. D., Layden, E. A., Gowins, J. R., Buchanan, A., \& Gollan, J. K. (2018). Functional connectivity of reflective and brooding rumination in depressed and healthy women. Cogn Affect Behav Neurosci, 18, 884-901. https://doi.org/10.3758/s13415-018-0611-7

45. Sheline, Y. I., Barch, D. M., Price, J. L., Rundle, M. M., Vaishnavi, S. N., Snyder, A. Z. ... Raichle, M. E. (2009). The default mode network and selfreferential processes in depression. Proc Natl Acad Sci U S A, 106, 1942-1947. https://doi.org/10.1073/pnas.0812686106

46. Sheline, Y. I., Price, J. L., Yan, Z., \& Mintun, M. A. (2010). Resting-state functional MRI in depression unmasks increased connectivity between networks via the dorsal nexus. Proc Natl Acad Sci U S A, 107, 11020-11025. https://doi.org/10.1073/pnas.1000446107

47. Spalding, K. N., Schlichting, M. L., Zeithamova, D., Preston, A. R., Tranel, D., Duff, M. C., \& Warren, D. E. (2018). Ventromedial Prefrontal Cortex Is Necessary for Normal Associative Inference and Memory Integration. J Neurosci, 38, 3767-3775. https://doi.org/10.1523/jneurosci.250117.2018

48. Wang, S., Zhao, Y., Zhang, L., Wang, X., Wang, X., Cheng, B. ... Gong, Q. (2019). Stress and the brain: Perceived stress mediates the impact of the superior frontal gyrus spontaneous activity on depressive symptoms in late adolescence. Hum Brain Mapp, 40, 4982-4993. https://doi.org/10.1002/hbm.24752

49. Yang, R., Gao, C., Wu, X., Yang, J., Li, S., \& Cheng, H. (2016). Decreased functional connectivity to posterior cingulate cortex in major depressive disorder. Psychiatry Res Neuroimaging, 255, 15-23. https://doi.org/10.1016/j.pscychresns.2016.07.010

50. Zhang, R., Geng, X., \& Lee, T. M. C. (2017). Large-scale functional neural network correlates of response inhibition: an fMRI meta-analysis. Brain Struct Funct, 222, 3973-3990. https://doi.org/10.1007/s00429-017-1443-x

51. Zhang, R., Kranz, G. S., Zou, W., Deng, Y., Huang, X., Lin, K., \& Lee, T. M. C. (2020). Rumination network dysfunction in major depression: A brain connectome study. Prog Neuropsychopharmacol Biol Psychiatry, 98, 109819. https://doi.org/10.1016/j.pnpbp.2019.109819 
52. Zhang, Y. F., Han, Y., Wang, Y. Z., Zhang, Y. F., Jia, H. X., Jin, E. H. ... Li, L. (2015). Characterization of resting-state fMRI-derived functional connectivity in patients with deficiency versus excess patterns of major depression. Complement Ther Med, $23,7-13$. https://doi.org/10.1016/j.ctim.2014.12.010

53. Zhou, H. X., Chen, X., Shen, Y. Q., Li, L., Chen, N. X., Zhu, Z. C. ... Yan, C. G. (2020). Rumination and the default mode network: Meta-analysis of brain imaging studies and implications for depression. Neuroimage, 206, 116287. https://doi.org/10.1016/j.neuroimage.2019.116287

54. Zhu, X., Wang, X., Xiao, J., Liao, J., Zhong, M., Wang, W., \& Yao, S. (2012). Evidence of a dissociation pattern in resting-state default mode network connectivity in first-episode, treatment-naive major depression patients. Biol Psychiatry, 71, 611-617.

https://doi.org/10.1016/j.biopsych.2011.10.035

\section{Figures}

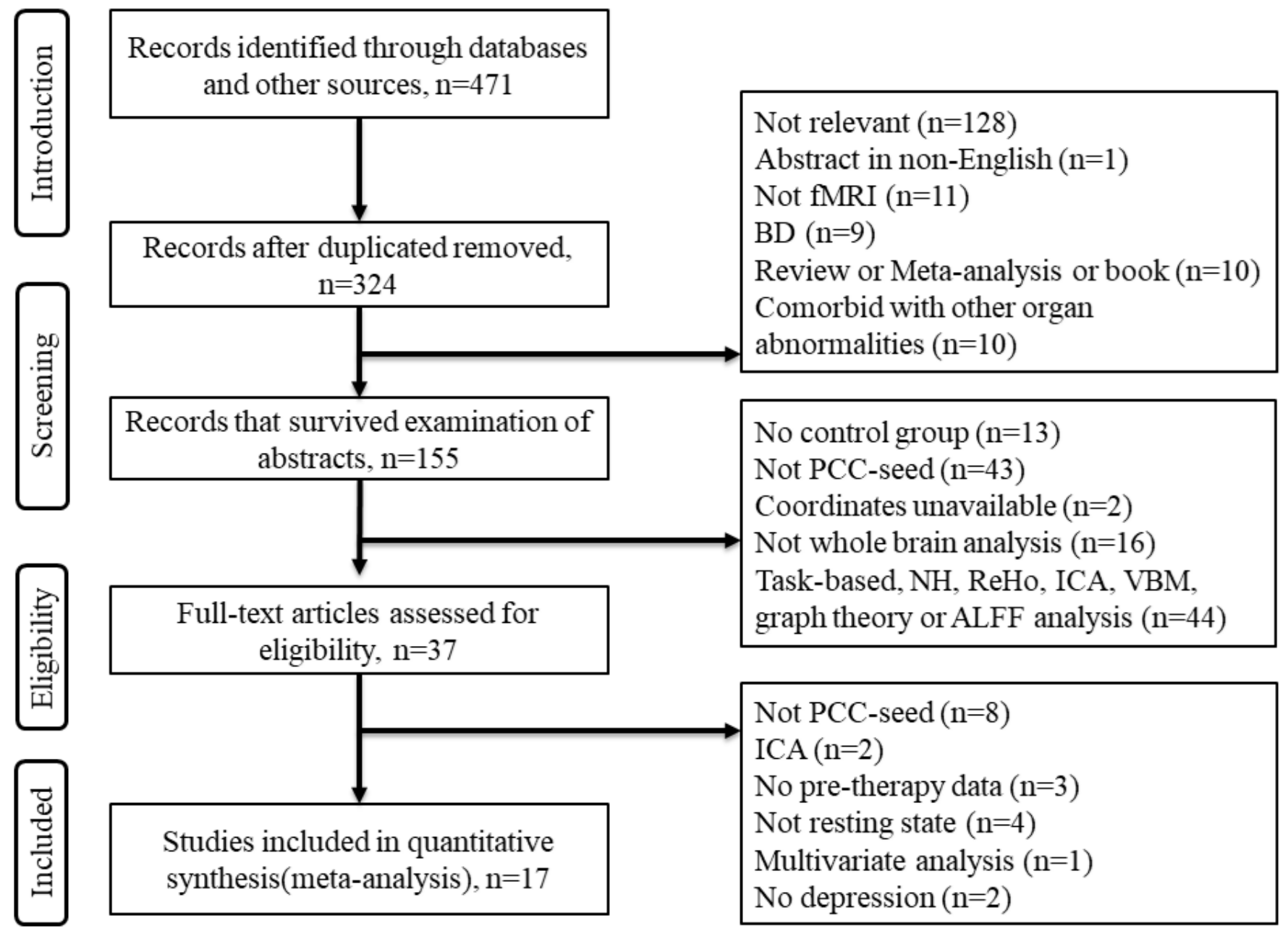

Figure 1

Flow chart of the identification of articles. BD, bipolar disorder; PCC, posterior cingulate; NH, network homogeneity; ReHo, regional homogeneity; ICA, independent component analysis; VBM, voxel-based morphometry; ALFF, amplitude low-frequency fluctuation. 


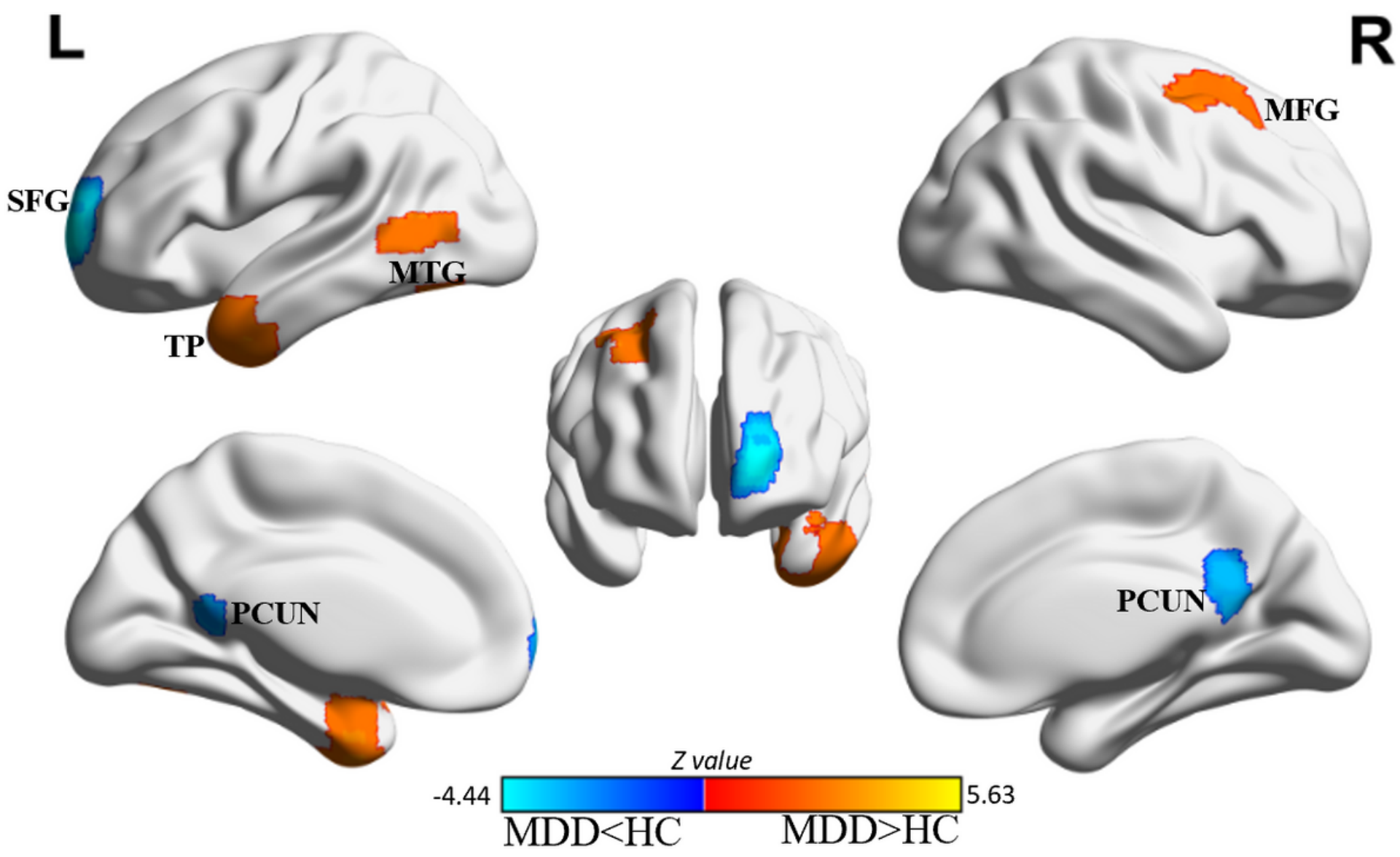

\section{Figure 2}

Regions showing increased (warm coded) and decreased (cold coded) functional connectivity with the PCC in patients with major depressive disorder compared to healthy controls. SFG, superior frontal gyrus; MTG, middle temporal gyrus; TP, temporal pole; PCUN, precuneus; MFG, middle frontal gyrus; $L(R)$, left (right) hemisphere. 
(a) Aberrant PCC functional connectivity profile in MDD
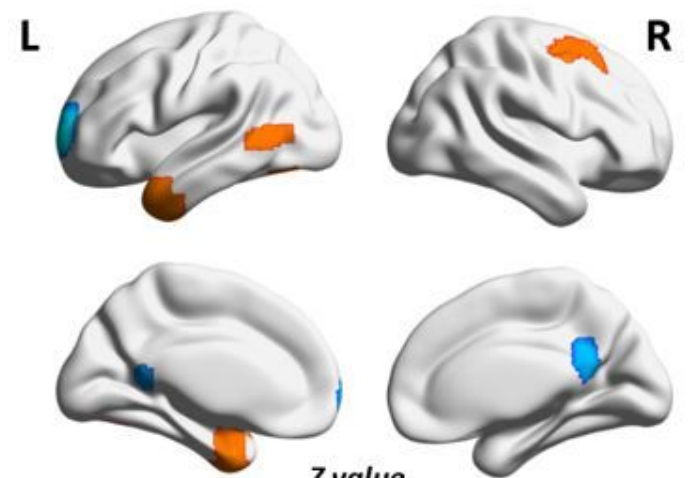
$-4.44$ Zvalue

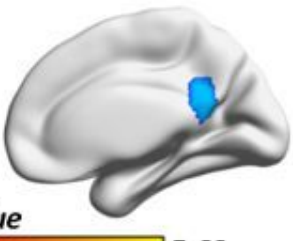

5.63 (b) Aberrant gray matter density in MDD

L
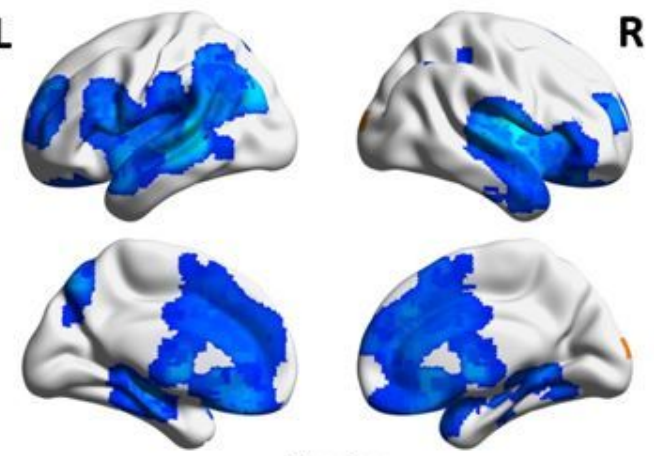

\section{Z value}

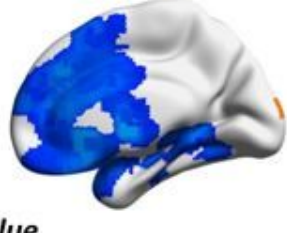

$-6.2 \square 3.3$

(C) Overlap pattern

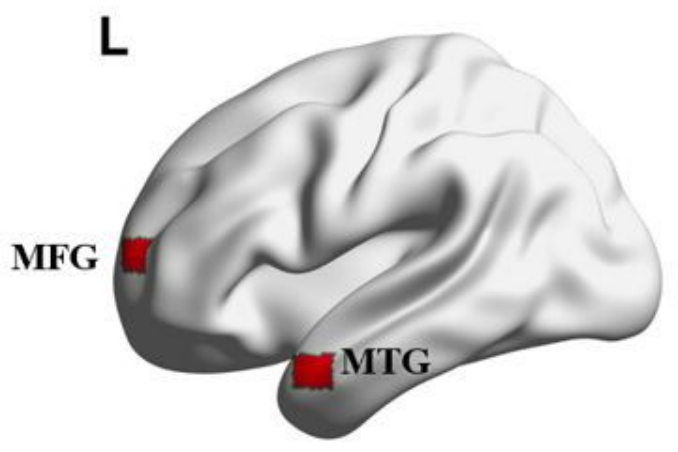

Figure 3

Meta-analytic results of VBM and overlapped regions of aberrant PCC-based functional connectivity profile and VBM analyses. (a) PCC-based functional connectivity profile; (b) Meta-analytic results of VBM; (C) overlapped regions of the two methods. VBM, voxel-based morphometry. 
(a)
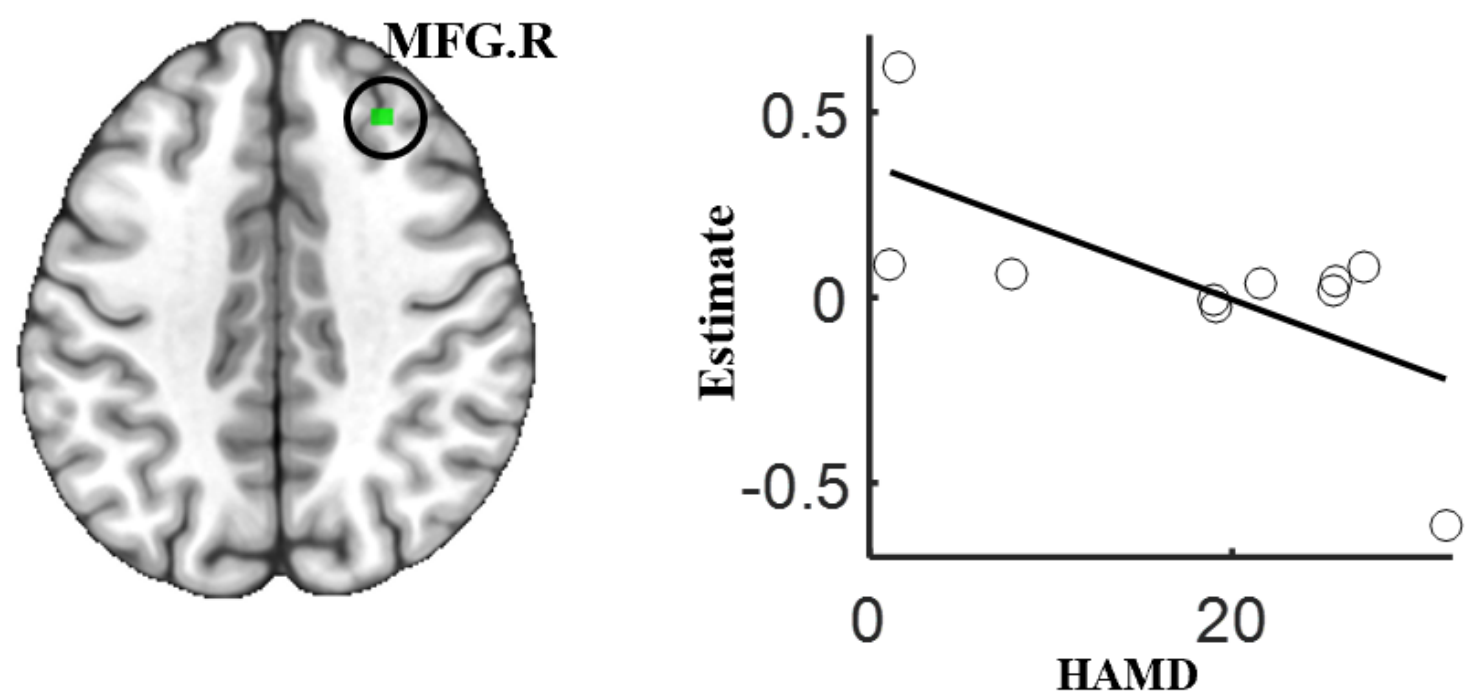

(b)
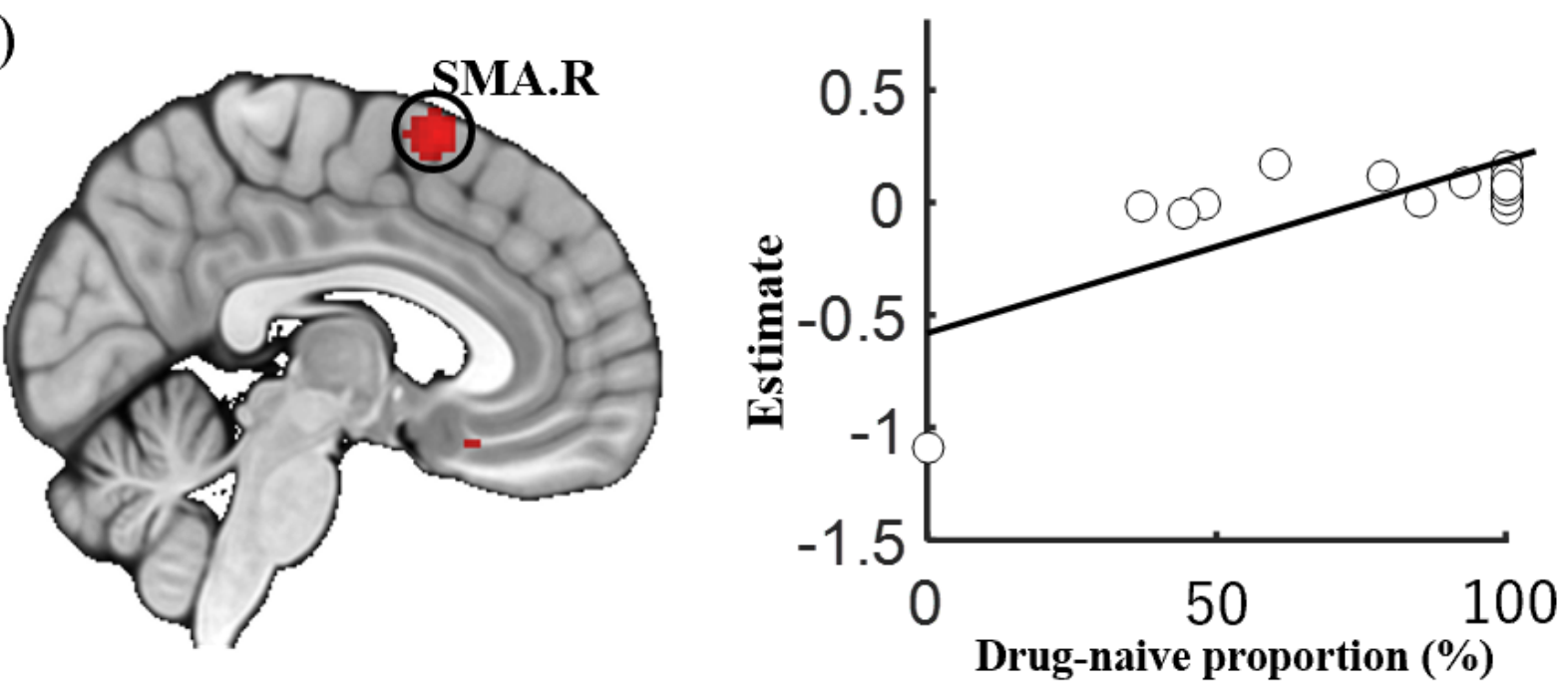

Figure 4

Results of meta-regression. (a) meta-regression with the depressive severity; (b) meta-regression with the percentage of drug native patients. SMA, supplementary motor area.

\section{Supplementary Files}

This is a list of supplementary files associated with this preprint. Click to download.

- Checklist.docx

- PCCMetaSuppSubmitted20210617.docx 